\title{
Awareness and use of intertrochanteric osteotomies in current clinical practice. An international survey
}

\author{
D. Haverkamp • H. Eijer • P. P. Besselaar • R. K. Marti
}

Received: 1 June 2006 /Revised: 22 August 2006 / Accepted: 24 August 2006 / Published online: 13 April 2007

(C) Springer-Verlag 2007

\begin{abstract}
Current literature shows that intertrochanteric osteotomies can produce excellent results in selected hip disorders in specific groups of patients. However, it appears that this surgical option is considered an historical one that has no role to play in modern practice. In order to examine current awareness of and views on intertrochanteric osteotomies among international hip surgeons, an online survey was carried out. The survey consisted of a set of questions regarding current clinical practice and awareness of osteotomies. The second part of the survey consisted of five clinical cases and sought to elicit views on preoperative radiological investigations and preferred (surgical) treatments. The results of our survey showed that most of these experts believe that intertrochanteric osteotomies should still be performed in selected cases. Only $56 \%$ perform intertrochanteric osteotomies themselves and of those, only $11 \%$ perform more than five per year. The responses to the cases show that about $30-40 \%$ recommend intertrochanteric osteotomies in young symptomatic patients. This survey shows that the role of intertrochanteric osteotomies is declining in clinical practice.
\end{abstract}

Résumé La littérature montre que les ostéotomies intertrochantériennes peuvent donner de bons résultats dans des indications précises. Cependant il apparait que cette opération est considérée comme historique, sans rôle à

D. Haverkamp $(\bowtie) \cdot$ P. P. Besselaar • R. K. Marti

Academic Medical Centre,

Orthotrauma Research Centre Amsterdam (G4-No), P.O. Box 22660, NL-1100 DD Amsterdam, The Netherlands e-mail: D.Haverkamp@osteotomie.nl

H. Eijer

Clinic Sonnenhof, Department of Orthopaedic Surgery,

Bern, Switzerland jouer dans une pratique moderne. Pour apprécier les idées actuelles sur ces ostéotomies parmi les chirurgiens de la hanche, une enquête a été faite par courrier électronique. Cette étude comportait une série de questions concernant les pratiques cliniques et la connaissance des ostéotomies inter trochantériennes. Une seconde partie concernait 5 cas cliniques et il était demandé les investigations radiologiques et les traitements proposés. Les résultats de cette étude montraient que la plupart des experts pensait que ces ostéotomies pouvaient être faites dans des cas sélectionnés. Seulement $56 \%$ font des ostéotomies intertrochantériennes et parmi eux, seulement $11 \%$ en font plus de 5 par an. Les réponses aux cas cliniques montraient que 30 à $40 \%$ préconise ces ostéotomies chez des patients jeunes et symptomatiques. Cette étude montre que le rôle de l'ostéotomie intertrochantérienne est déclinant en pratique clinique.

\section{Introduction}

The use of intertrochanteric osteotomies appears to be declining in current clinical practice. It seems that many orthopaedic surgeons consider it an historical operation that has lost its place in current hip-disorder treatment. There are many retrospective studies showing overall unsatisfactory results (Table 1) $[1,2,4,6,9-10,13,16-18,20,21$, 23-28, 30]. However, many of these included elderly patients with advanced stages of primary osteoarthritis (OA). The same studies showed that the outcome in younger patients with early-onset secondary osteoarthritis was good. However, only a few of these studies showed survival rates identical or superior to those of total hip replacements and then only in selected patient groups. In a recent long-term follow-up study, we demonstrated that, for specific hip disorders, intertrochanteric osteotomies can 


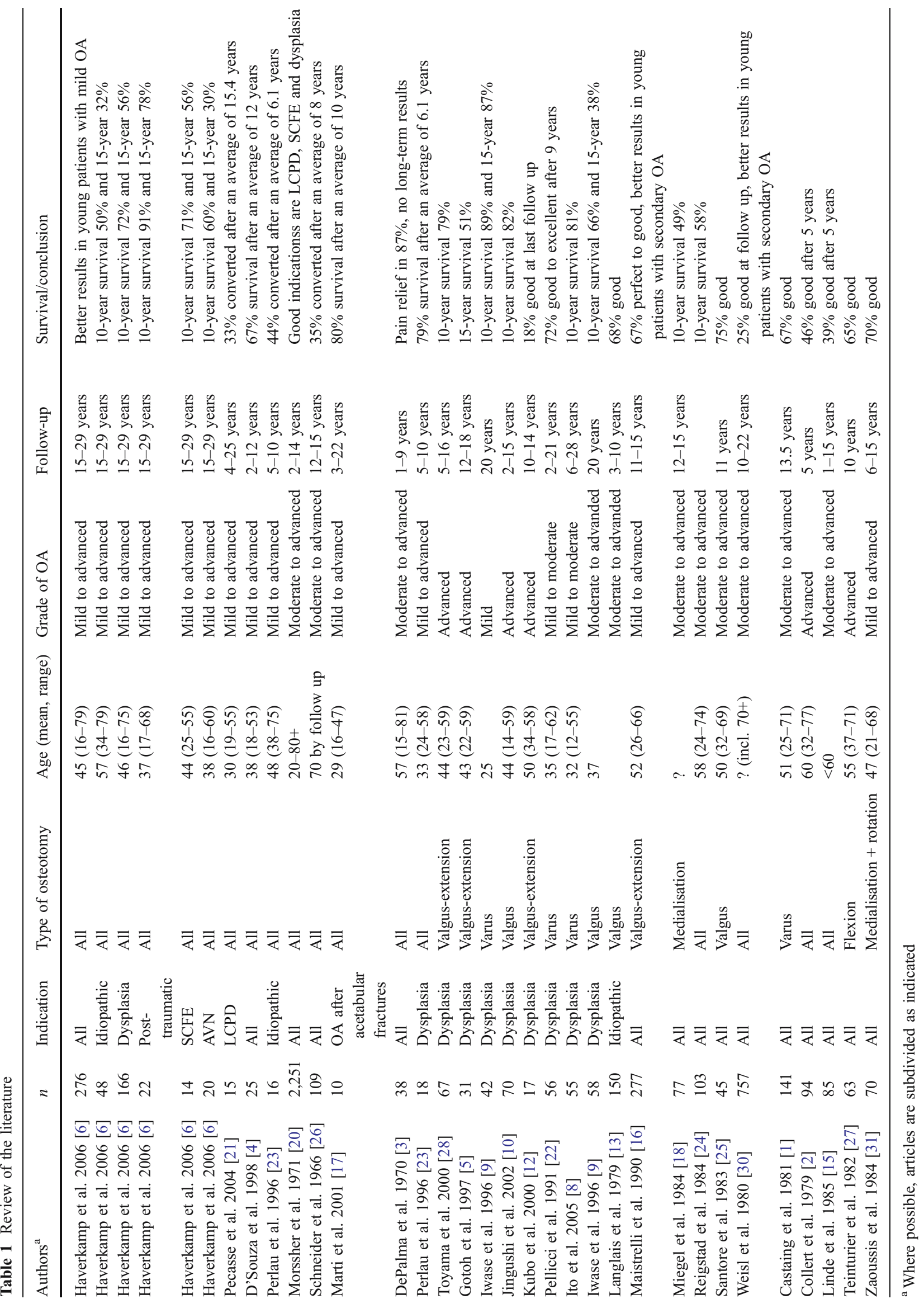


achieve good to excellent long-term results [6]. Several recent reviews presented the same message, namely that intertrochanteric osteotomies should not be forgotten as a treatment option in these selected cases [19, 29]. Since we believed that this view was not shared universally, we initiated an online international survey to investigate current awareness among orthopaedic hip surgeons about these selected groups and to map the current clinical use of intertrochanteric osteotomies.

\section{Methods}

We developed a questionnaire consisting of two sections. The first section consisted of questions dealing with the use of intertrochanteric osteotomy in clinical orthopaedic practice. To assess orthopaedic surgeons' awareness, the second part of the questionnaire consisted of questions related to five clinical cases. These cases were taken from our own long-term follow-up series and the long-term outcome of the performed intertrochanteric osteotomy was known in each case [6]. The responders were unaware of the treatment these patients received. Table 2 shows the full questionnaire (cases excluded).

An invitation to respond online to the questionnaire was sent to all members of the American Association of Hip and Knee Surgeons, all members of the British Hip Society and members of the Dutch Orthopaedic Society.

In order to identify factors that influenced surgeons to opt for an intertrochanteric osteotomy, a statistical analysis of the required data was carried out using a Pearson correlation analysis in which $P<0.05$ was considered as significant.

\section{Results}

One thousand invitations were sent by mail with an online return of 162 questionnaires. Since all responses were anonymous, no reminders or second invitations could be sent to non-responders. There were 69 responders from the United States and 93 from Europe.

From the content of the responses, we assume that all responders are orthopaedic surgeons with a special interest in hip surgery. Of all respondents, $96 \%$ believe that there is still a place for intertrochanteric osteotomy in current clinical practice with $56 \%$ still performing these. Only $11 \%$ perform more than five osteotomies per year.

The indications that are considered valid for performing intertrochanteric osteotomies are given in Table 3.

In the workup of hip disorders, $87 \%$ of surgeons ask for an AP pelvic radiograph and $85 \%$ a lateral radiograph. False profile views instead of lateral views are added only by $62 \%$. A CT scan is routinely requested by $29 \%$ and an additional MRI by $17 \%$. Only $3 \%$ requested an MR arthrography.

When the issue of performing a THR after a previous intertrochanteric osteotomy was raised, $83 \%$ regarded this as a more challenging operation. Thirty-four percent believed that the long-term results of THR after a previous osteotomy would be impaired. This view appeared to have no bearing on the decision whether osteotomies should still be performed. Of the surgeons who perform osteotomies themselves, $46 \%$ think that the long-term outcome of a subsequent THR is impaired. In the case of surgeons who did not perform osteotomies, this figure increased to $68 \%$ (chi-square not significant).

When a sub-analysis was performed comparing responses from orthopaedic surgeons from the United States with those from Europe, the only significant differences were found in the performance and indication. In Europe, $69 \%$ of the questioned surgeons perform intertrochanteric osteotomies; in the United States only 39\% (chi-square $P<0.01$ ). In Europe, $33 \%$ believed that selected patients with idiopathic OA could benefit from an ITO; in the USA, this was only $9 \%$ (chi-square $P<0.01$ ). Also for post-Perthes deformities (Europe 50\%, USA 27\%) and post-traumatic deformities (Europe $41 \%$, USA 16\%), significant differences were present (chi-square both $P<0.01$ ). No significant regional differences were present in preoperative screening.

Although it is not possible to show all X-rays from the cases in this article, we attempt to give an impression by presenting the neck-shaft angle (CCD) as an indicator of coxa valga, the Sharp angle as an indication of the steepness of the acetabulum, and the CE angle according to Wiberg and the acetabular head index (AHI) as indicators of dysplasia and lateralisation.

The severity of osteoarthritis was graded according to Tönnis. Complaints were scored using the Merle d'Aubigne score.

In case 1, we presented a 34-year-old female with a coxa valga $\left(\mathrm{CCD} 140^{\circ}\right.$ ) and mild dysplasia (Sharp angle $50^{\circ}$, CE $22^{\circ}$ and AHI 0.7) with mild OA (Tönnis grade 1) and a Merle d'Aubigne score of 13. In addition to a pelvic X-ray and an abduction correction view, $64 \%$ requested additional investigations. These were mainly false profiles $(35 \%)$, lateral X-rays (32\%) and CT scans (30\%). As a treatment option, an intertrochanteric osteotomy was mentioned by $32 \%$, an acetabular realigning osteotomy (also known as periacetabular osteotomy, PAO) by $28 \%$ and a THR by $4 \%$ (Fig. 1). We performed a $15^{\circ}$ varus osteotomy, which was converted to a THA after 21 years.

In case 2 , we presented a 55-year-old female with a coxa valga $\left(\mathrm{CCD} 139^{\circ}\right)$ and minimal dysplasia (Sharp angle $43^{\circ}$, CE $24^{\circ}$ ) with moderate OA (Tönnis grade 2) and a Merle 
Table 2 Questions from the survey

\section{Questions}

Occupation: Orthopaedic Surgeon/Orthopaedic Resident/Other

Age: $<30$ years $/ 30-50$ years $/>50$ years

Question 1:

Is there still a place for intertrochanteric osteotomies (ITO) in the treatment of primary or secondary osteoarthritis? No/Yes/Yes, but only in young patients/Yes, but only in some special cases Question 2:

Do you perform intertrochanteric osteotomies yourself? Yes/No

If Yes, how many per year?

Question 3a:

Do you investigate the possibility of performing an ITO in (selected) patients with osteoarthritis of the hip? Yes/No

Question 3b:

If Yes, for which types of osteoarthritis do you consider an osteotomy? Idiopathic OA

OA secondary to acetabular dysplasia

OA secondary to coxa valga

OA secondary to Legg-Calvé-Perthes disease

OA secondary to slipped capital femoral epiphysis

Post-traumatic OA

Question 4:

Is 3-D CT scanning necessary for the planning of an ITO? Yes/No

Question 5:

Which kind of radiological investigation is necessary to plan an ITO in your opinion? (several options are possible)

Plain pelvic X-ray

Abduction and/or adduction correction views

X-ray according to Dunn

False profile

Lateral hip X-ray

CT scan

CT scan with 3-D reconstruction

MRI

Arthro-MRI

Question 6:

Do you consider a total hip replacement after a previous osteotomy to be a more challenging operation? Yes/No

Question 7:

Do you think that the long-term results of total hip replacement after a previous osteotomy are worse than the results of a primary THR?

Yes, worse than the long-term results of a primary THR/No, both

long-term results are comparable

Question 8:

Is there, in your opinion, an age limit for performing an ITO? Yes/No

d'Aubigne score of 9. In addition to a pelvic X-ray and an abduction/adduction correction view as shown, $28 \%$ requested additional investigations. As a treatment option, an intertrochanteric osteotomy was mentioned by $9 \%$, an acetabular realigning osteotomy by $1 \%$ and a THR by $70 \%$. We performed a $10^{\circ}$ valgus osteotomy, which was converted to a THA after 9.4 years.

In case 3 , we presented a young female (31 years of age) with minimal complaints and mild dysplasia (sharp angle
Table 3 Indications for which intertrochanteric osteotomies are still considered

\begin{tabular}{ll}
\hline Indication & $\%$ of respondents \\
\hline Idiopathic OA & 23 \\
Dysplasia & 51 \\
Coxa valga & 65 \\
Legg-Calvé-Perthes disease & 40 \\
Slipped capital femoral epiphysis & 53 \\
Post-traumatic deformities & 31 \\
\hline
\end{tabular}

$50^{\circ}$ and $\mathrm{CE}$ angle of $14^{\circ}$ ) without significant osteoarthritic changes (Fig. 1). The majority advised conservative treatment (58\%). In this case, $21 \%$ requested additional MRI scanning and $22 \%$ requested additional false profile X-rays. We performed a $15^{\circ}$ varus osteotomy. After 19 years the patient had a Merle d'Aubigne score of 13 .

In case 4 , we described an 18-year-old female with a symptomatic (Merle d'Aubigne 16) excessive femoral anteversion (CCD $140^{\circ}$ anteversion $38^{\circ}$ ) with a normal acetabulum (Sharp angle $38^{\circ}$ and $\mathrm{CE}$ angle $36^{\circ}$ ). In addition to a pelvic X-ray and a Dunn X-ray, 49\% requested additional investigations and $50 \%$ of these requested an MRI. The suggested treatment consisted of conservative treatment in $43 \%$ and an intertrochanteric osteotomy in $41 \%$. We performed a slight varus and $20^{\circ}$ derotation osteotomy (at both hips) and after 20 years, the patient had a Merle d'Aubigne score of 15 (and 18 for the contra lateral hip).

In case 5, a typical post-Perthes deformity was shown in a 28-year-old male with progressive complaints. In addition to the presented pelvic X-ray and adduction correction view, 44\% requested additional investigations, mainly lateral views and $\mathrm{CT}$ scans. The suggested treatment consisted of conservative treatment in $43 \%$ and an intertrochanteric osteotomy in $33 \%$. We performed a valgus osteotomy; after 14 years, the patient had a Merle d'Aubigne score of 17.

Figure 2 shows a summary of suggestions made in the five cases. Overall, intertrochanteric osteotomies were advised by $30-40 \%$ in symptomatic young patients. One case consisted of an older female patient (case 2) with a symptomatic OA secondary to dysplasia, in which mainly THR was advised.

In the cases concerning younger patients, $44-63 \%$ of the respondents requested additional radiological investigations. In cases 1 and 5 , these were mainly false profile views and $\mathrm{CT}$ scans; in case 3 , mainly false profile views and MRIs; and in case 4, mainly CT scans and MRIs.

Responders were divided into two age groups: younger and older than 50. Apart from their responses in cases of post-traumatic deformities (young $40 \%$, older $22 \%$, chisquare $P<0.05$ ), no significant differences were present. 


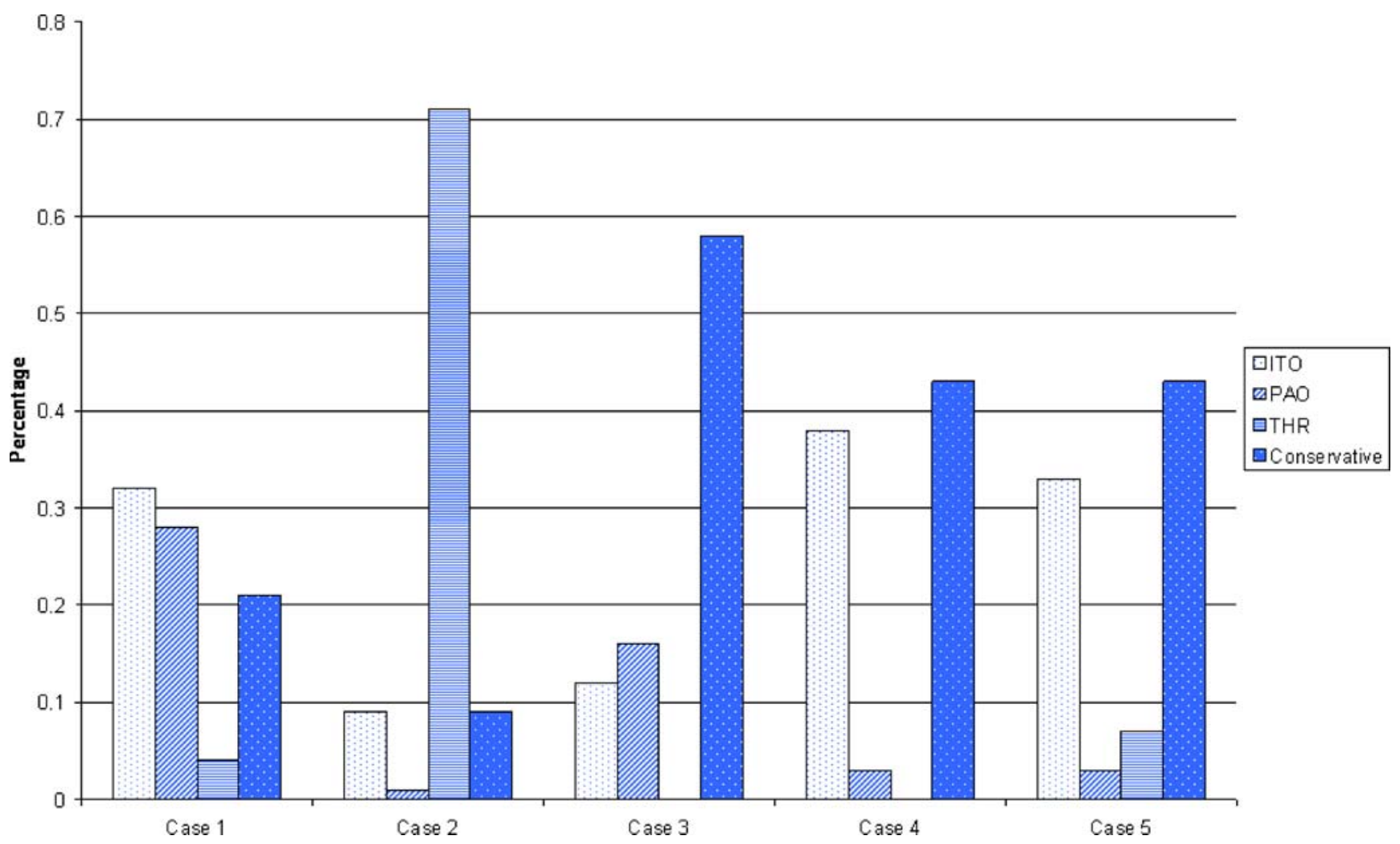

Fig. 1 Suggested interventions per case. Case 1 A 34-year-old female with symptomatic mild OA due to mild dysplasia and coxa valga. Case 2 A 55-year-old female with symptomatic moderate OA due to mild dysplasia and coxa valga. Case 3 A 31-year-old female with mild OA without significant complaints due to mild dysplasia and coxa valga.

Case 4 An 18-year-old female with symptomatic excessive femoral anteversion without OA changes. Case 5 A 28-year-old male with a symptomatic post-Perthes deformity without OA changes. ITO Intertrochanteric osteotomy, PAO periacetabular osteotomy, THR total hip replacement

The Pearson correlation analysis showed a significant correlation between THR and age $(R=0.91)$ and clinical complaints $(R=0.91)$. Conservative treatment showed a significant correlation with clinical complaints $(R=0.93)$.

\section{Discussion}

The aim of this survey was to show the role of the intertrochanteric osteotomy in current practice. Although almost all responders believe that intertrochanteric osteotomies should still play a role in modern medicine, only a few are performed nowadays. One should take into account that we primarily surveyed hip experts and not many general orthopaedic surgeons. Thus, the responses do not necessarily reflect common orthopaedic practice; however, we can assume that the use of intertrochanteric osteotomy by the non-specialised hip surgeon is probably even lower. This indicates that less reconstructive osteotomy surgery is performed nowadays and that the surgical know-how is in danger of being lost.

Of course, it is difficult to give accurate advice based on limited information and without seeing the patient; however it is possible to state a general opinion. The cases presented were selected in order to analyse the type of patients and hip deformities for which intertrochanteric osteotomies are considered and also to assess what type of radiological investigations are used in this decision-making process.

We believe that the cases presented are representative; however 45 (29\%) of the surgeons who indicated that there was a place for intertrochanteric osteotomies in clinical practice did not recommend an intertrochanteric osteotomy in any of the cases.

There was a clear consensus that osteotomies should be reserved for younger patients and that THR was indicated in the older patient. This is consistent with the results from the literature $[6,19,29]$.

The results of the survey showed a significant correlation between the level of symptoms and the choice for conservative treatment. One case consisted of a 31-yearold patient with minimal complaints (Merle d'Aubigne score 16 out of 18 ) with a mild dysplasia (Sharp angle $50^{\circ}$, $\mathrm{CE}$ angle $\left.14^{\circ}\right)$ and coxa valga (CCD $\left.140^{\circ}\right)$. In this case, $58 \%$ advised conservative therapy.

In patients already suffering from hip complaints (although only minor), it is thought that the development 

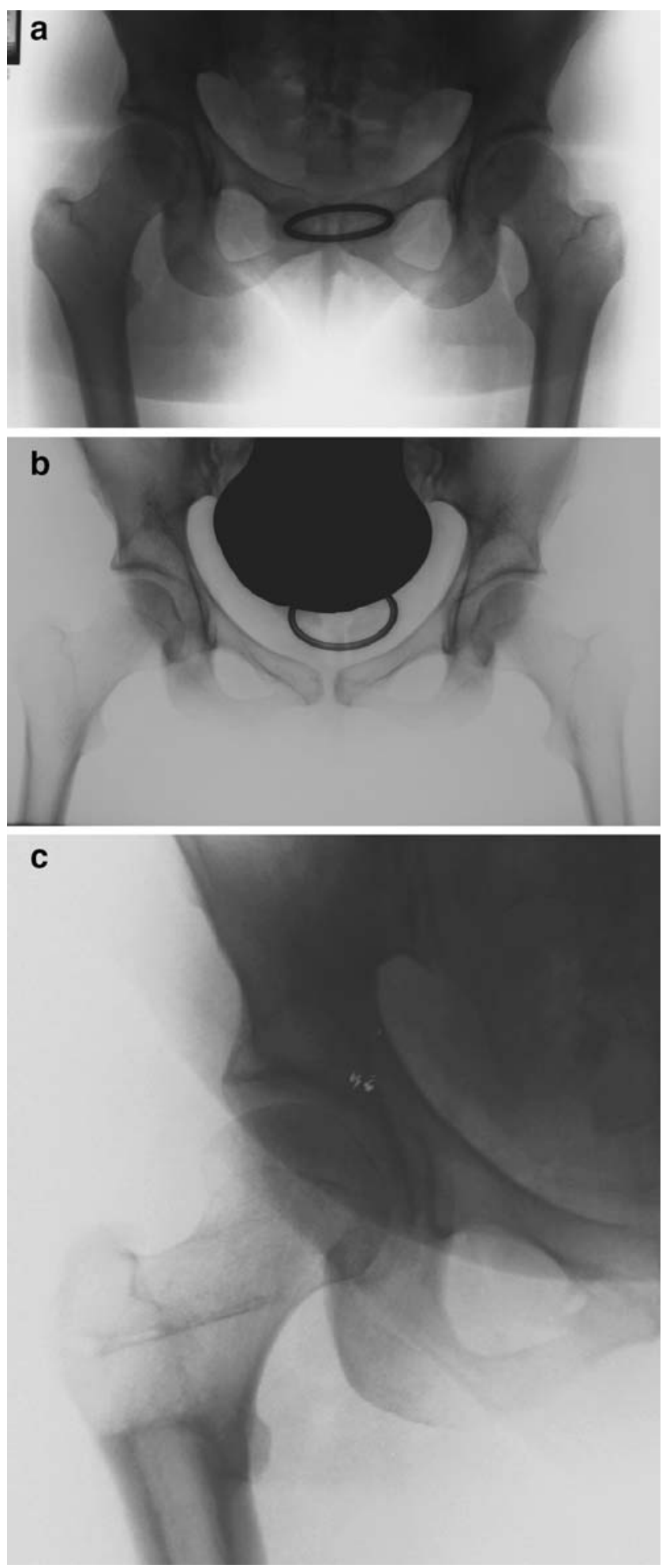

Fig. 2a-c Example of a case (case 3). a A 31-year-old female, with minor complaints of the right hip (Merle d'Aubigne score 16). ROM was full. Radiological measurements for right hip: Sharp angle $50^{\circ}$, $\mathrm{CE}$ angle $14^{\circ}, \mathrm{CCD} 140^{\circ}$. b Abduction correction view. c Long-term follow up after 18 years of OA is inevitable [11, 14]. Several authors have mentioned that, in these patients especially, early intervention could be rewarding [6, 9, 19, 23]. This view is clearly not shared commonly.

In hips where the main deformity is on the acetabular side, an acetabular realigning procedure is the preferred surgical choice. In hips where the problem on the acetabular side is mild and where there is also a problem on the femoral side, a femoral osteotomy could be just as effective. In our cases, two of these types of patients were included (cases 1 and 3). Those who chose joint-saving surgery were equally divided among PAO and ITO supporters. The available literature shows that good long-term results can be obtained with intertrochanteric osteotomies in these patients [6].

The declining role of osteotomies could also be caused by patient preferences. Modern patients mostly wish to have a quick result, which is easier to obtain with a THR than with an osteotomy. A second patient preference could be that patients are no longer satisfied with the good results that can be obtained with an osteotomy, but want the excellent results that a THR could probably provide. It is important for us to inform patients of the long-term effects that this decision could have and to advise osteotomies in those patients who could benefit from it.

Many orthopaedic surgeons believe that the long-term outcome of a subsequent THR is impaired after a previous osteotomy. This view does not seem to influence the decision as to whether to perform or recommend intertrochanteric osteotomies. In the literature, several reports on THR after osteotomies are available but with conflicting views. However, it appears that the long-term outcome of the THR is not impaired after a previous osteotomy [7].

Our survey shows that, even among experts, the role of intertrochanteric osteotomies is declining. Only a few are performed each year although most surgeons believe they should still be performed today. The current use of intertrochanteric osteotomy is limited to a select group of young and active patients. By identifying the right indications, we should preserve intertrochanteric osteotomies from complete extinction.

\section{References}

1. Castaing J, Marcillaud G (1981) Varus osteotomy in severe arthrosis of the hip-a long-term study [author's translation]. Rev Chir Orthop Reparatrice Appar Mot 67:267-277

2. Collert S, Gillstrom P (1979) Osteotomy in osteoarthritis of the hip. A prospective study. Acta Orthop Scand 50:555-561

3. DePalma AF, Rothman RH, Klemek JS (1970) Osteotomy of the proximal femur in degenerative arthritis. Clin Orthop Relat Res 73:109-115

4. D'Souza SR, Sadiq S, New AM, Northmore-Ball MD (1998) Proximal femoral osteotomy as the primary operation for young 
adults who have osteoarthrosis of the hip. J Bone Joint Surg Am 80:1428-1438

5. Gotoh E, Inao S, Okamoto T, Ando M (1997) Valgus-extension osteotomy for advanced osteoarthritis in dysplastic hips. Results at 12 to 18 years. J Bone Joint Surg Br 79(4):609-615

6. Haverkamp D, Eijer H, Patt TW, Marti RK (2006) Multi directional intertrochanteric osteotomy for primary and secondary osteoarthritisresults after 15 to 29 years. Int Orthop 30(1):615-620

7. Haverkamp D, de Jong PT, Marti RK (2006) Intertrochanteric osteotomies do not impair long-term outcome of subsequent cemented total hip arthroplasties. Clin Orthop Relat Res 444:154-160

8. Ito K, Matsuno T, Minami A (2005) Intertrochanteric varus osteotomy for osteoarthritis in patients with hip dysplasia: 628 years follow up. Clin Orthop Relat Res 433:124-128

9. Iwase T, Hasegawa Y, Kawamoto K, Iwasada S, Yamada K, Iwata H (1996) Twenty years' followup of intertrochanteric osteotomy for treatment of the dysplastic hip. Clin Orthop Relat Res $331: 245-255$

10. Jingushi S, Sugioka Y, Noguchi Y, Miura H, Iwamoto Y (2002) Transtrochanteric valgus osteotomy for the treatment of osteoarthritis of the hip secondary to acetabular dysplasia. J Bone Joint Surg Br 84:535-539

11. Klaue K, Durnin CW, Ganz R (1991) The acetabular rim syndrome. A clinical presentation of dysplasia of the hip. J Bone Joint Surg Br 73:423-429

12. Kubo T, Horii M, Yamaguchi J, et al (2000) Acetabular labrum in hip dysplasia evaluated by radial MRI. J Rheumatol 27:1955-1961

13. Langlais F, Roure JL, Maquet P (1979) Valgus osteotomy in severe osteoarthritis of the hip. J Bone Joint Surg Br 61-B:424-431

14. Leunig M, Beck M, Dora C, Ganz R (2006) Femoroacetabular impingement: trigger for the development of osteoarthritis. Orthopade 35:77-84

15. Linde F, Pallesen R (1985) Osteoarthritis of the hip in patients under 60 years of age. A study of the importance of pain at rest as an indication for intertrochanteric osteotomy. Arch Orthop Trauma Surg 104(5):267-270

16. Maistrelli GL, Gerundini M, Fusco U, Bombelli R, Bombelli M, Avai A (1990) Valgus-extension osteotomy for osteoarthritis of the hip. Indications and long-term results. J Bone Joint Surg Br 72:653-657

17. Marti RK, Chaldecott LR, Kloen P (2001) Intertrochanteric osteotomy for posttraumatic arthritis after acetabular fractures. J Orthop Trauma 15:384-393
18. Miegel RE, Harris WH (1984) Medial-displacement intertrochanteric osteotomy in the treatment of osteoarthritis of the hip. A long-term follow-up study. J Bone Joint Surg Am 66:878-887

19. Millis MB, Kim YJ (2002) Rationale of osteotomy and related procedures for hip preservation: a review. Clin Orthop 405:108-121

20. Morsscher E (1971) Die intertrochantere Osteotomie bei Coxarthrose. Verlag Hans Huber, Bern

21. Pecasse GA, Eijer H, Haverkamp D, Marti RK (2004) Intertrochanteric osteotomy in young adults for sequelae of Legg-Calve-Perthes' disease-a long term follow-up. Int Orthop 28:44-47

22. Pellicci P, Hu S, Garvin K, Salvati E, Wilson PJ (1991) Varus rotational femoral osteotomies in adults th hip dysplasia. Clin Orthop Relat Res 272:162-166

23. Perlau R, Wilson MG, Poss R (1996) Isolated proximal femoral osteotomy for treatment of residua of congenital dysplasia or idiopathic osteoarthrosis of the hip. Five to ten-year results. J Bone Joint Surg Am 78:1462-1467

24. Reigstad A, Gronmark T (1984) Osteoarthritis of the hip treated by intertrochanteric osteotomy. A long-term follow-up. J Bone Joint Surg Am 66:1-6

25. Santore RF, Bombelli R (1983) Long-term follow-up of the Bombelli experience with osteotomy for osteoarthritis: results at 11 years. Hip 1983:106-128

26. Schneider R (1966) Mehrjahreresultate eines Kollektivs von 100 intertrochanteren Osteotomien bei Coxarthrose. Helv Chir Acta 33:185-205

27. Teinturier P, Levai JP, Collin JP, Terver S (1982) Intertrochanteric flexion osteotomy as an only alternative to total hip arthroplasty in advanced osteoarthritis. A ten-year follow-up. Clin Orthop Relat Res 166:158-161

28. Toyama H, Endo N, Sofue M, Dohmae Y, Takahashi HE (2000) Relief from pain after Bombelli's valgus-extension osteotomy, and effectiveness of the combined shelf operation. J Orthop Sci 5:114-123

29. Turgeon TR, Phillips W, Kantor SR, Santore RF (2005) The role of acetabular and femoral osteotomies in reconstructive surgery of the hip: 2005 and beyond. Clin Orthop Relat Res 441:188-199

30. Weisl H (1980) Intertrochanteric osteotomy for osteoarthritis. A long-term follow-up. J Bone Joint Surg Br 62-B:37-42

31. Zaoussis AL, Adamopoulos G, Geraris G, Manoloudis M, Galanis I (1984) Osteotomy for osteoarthritis of the hip. A clinical and radiological survey. Int Orthop 7(4):223-228 